\title{
POSTERIOR INTEROSSEOUS NERVE PALSY IN RHEUMATOID
}

\section{ARTHRITIS}

\author{
STEPHEN H. WHITE, JOHN W. GOODFELLOW, ALASTAIR MOWAT \\ From the Nuffield Orthopaedic Centre, Oxford
}

\begin{abstract}
Bilateral posterior interosseous nerve palsy in a rheumatoid patient is described. Six previous case reports and our experience indicate that steroid injection into the elbow may not produce lasting recovery and may lead to unacceptable delay before surgical decompression.

An anterolateral approach for division of the arcade of Frohse is effective in cases with diffuse synovitis; where there is a local cystic swelling a posterolateral approach provides better access. Good recovery of nerve function can be expected after early operation.
\end{abstract}

Rheumatoid synovitis of the elbow joint may cause posterior interosseous nerve palsy by compressing the nerve against the arcade of Frohse. The resulting syndrome of weakness of extension of the digits without sensory disturbance is easily mis-diagnosed in a rheumatoid patient as extensor tendon rupture. Late diagnosis of the true cause may result in permanent paralysis (Millender, Nalebuff and Holdsworth 1973). Six other cases have been reported in the English literature (Marmor, Lawrence and Dubois 1967; Chang et al. 1972; Millender et al. 1973; Roth et al. 1986). There is no agreed method of management of this condition, which has been variously treated by systemic steroids (Chang et al. 1972), local steroid injection (Marmor et al. 1967; Millender et al. 1973), and surgical decompression by various routes (Marmor et al. 1967; Roth et al. 1986).

We describe the unique case of a patient with bilateral posterior interosseous nerve palsy who underwent surgical decompression on both sides after initial treatment with steroid injections on one side. By comparing the outcome of the reported cases we draw some conclusions about the management of this condition.

\section{CASE HISTORY}

The left side. A 69-year-old retired farmer had a threeyear history of seropositive erosive rheumatoid arthritis of moderate severity, controlled with non-steroidal anti-

S. H. White, FRCS, Orthopaedic Registrar

J. W. Goodfellow, MS, FRCS, Consultant Orthopaedic Surgeon

A. Mowat, FRCP, Consultant Rheumatologist

Nuffield Orthopaedic Centre, Headington, Oxford OX3 7LD, England.

Correspondence should be sent to $\mathrm{Mr} \mathrm{S}$. H. White.

(C) 1988 British Editorial Society of Bone and Joint Surgery $0301-620 \times / 88 / 3100 \$ 2.00$

$J$ Bone Joint Surg $[\mathrm{Br}] 1988$;0-B:468-71. inflammatory and anti-malarial drugs. He had never received systemic steroids. He awoke one morning unable to fully extend the fingers of his left hand. This weakness increased over the ensuing week and he noticed discomfort in his left elbow.

On examination he had weakness of extensor digitorum communis and of extensor pollicis longus. Wrist extension was also weak and when attempted produced radial deviation. Wasting of the extensor compartment of the forearm created a gutter bordered by the well preserved brachioradialis and extensor carpi radialis longus. A soft-tissue mass was palpable over the lateral aspect of the neck of the radius and movements of the elbow were restricted and painful. Sensation throughout the limb was normal. Rupture of the extensor communis tendon was excluded by the tenodesis test: passive flexion of the patient's wrist caused extension of the digits, proving continuity of the extensor tendons.

Plain radiographs of the elbow showed moderately severe rheumatoid disease with subluxation of the radiohumeral joint. Elbow arthrography showed that the swelling was a cyst overlying the neck of the radius which communicated with the synovial cavity of the joint (Fig. 1). Electrophysiological examination showed severe denervation of all the muscles supplied by the posterior interosseous nerve.

Exploration was undertaken six weeks after the onset of symptoms using a modified posterolateral approach (Henry 1973). The fascia between extensor carpi radialis brevis and extensor digitorum communis was divided to reveal the glistening fibres of the supinator muscle which was bulging forwards and laterally (Fig. 2). A small muscle-splitting incision was made through the superficial layer of supinator at a point three finger breadths from the neck of radius. This exposed the plane between the two layers of supinator, but the nerve was located only after complete division of the superficial layer because it had been displaced anteriorly. At the proximal edge of supinator a constrict- 


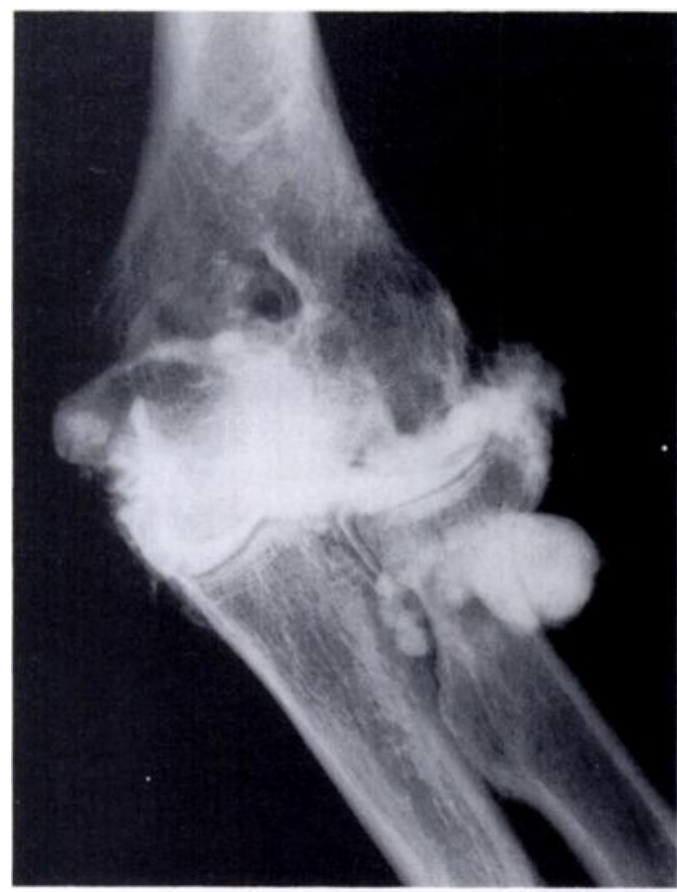

Fig. 1

Arthrography of the left elbow reveals the cyst overlying the neck of the radius which has caused compression of the posterior interosseous nerve.

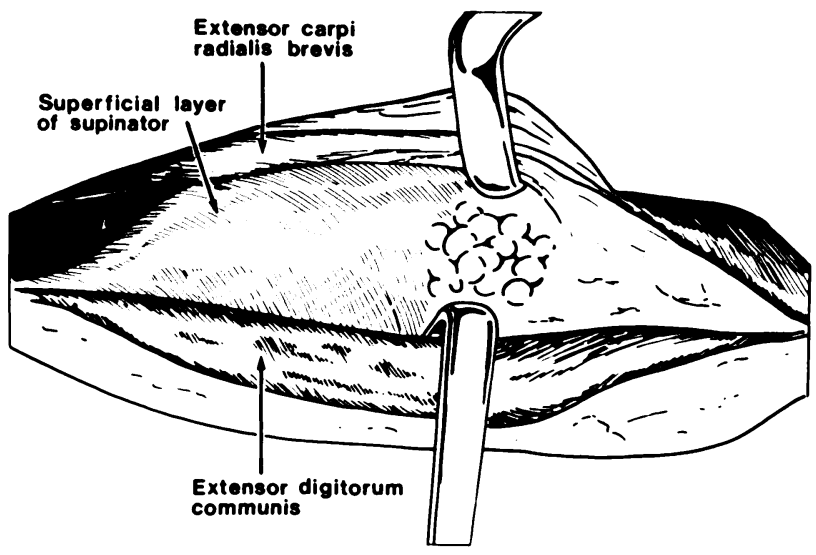

Fig. 2

Posterolateral approach. The fascia between extensor carpi radialis brevis and extensor digitorum communis has been divided to reveal the glistening fibres of supinator.

ing band of fibres, which overlay the nerve, was divided (Fig. 3). This band was the arcuate ligament of Frohse (Frohse and Fränkel 1908). The elbow was entered but, despite the evacuation of $20 \mathrm{ml}$ of synovial fluid, the cystic swelling did not deflate. Division of the orbicular ligament and the deep layer of supinator was needed to deliver the swelling, which was adherent to the radial neck at the anterior margin of the superior radio-ulnar joint (Fig. 4). The swelling was excised and found to consist of thick synovium. The operation was completed by excision of the radial head and synovectomy of the

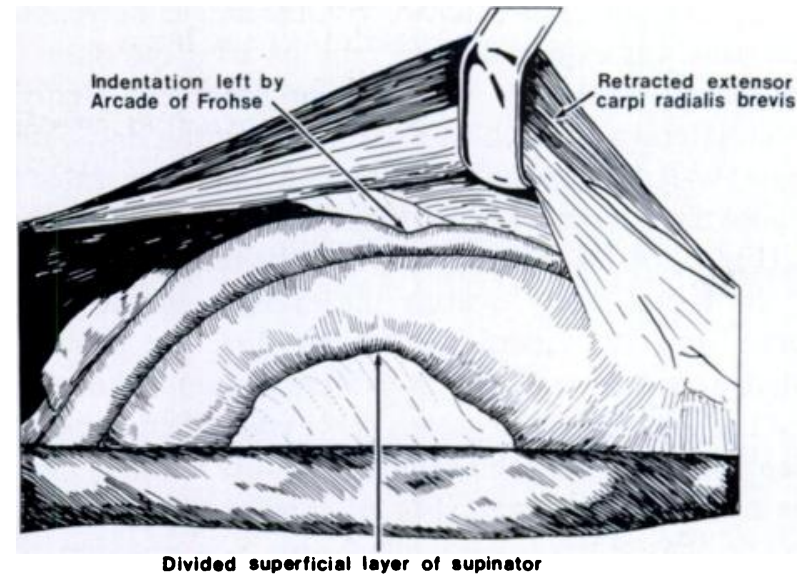

Fig. 3

The superficial layer of supinator has been divided to reveal the posterior interosseous nerve indented by the proximal rim of supinator: the arcade of Frohse.

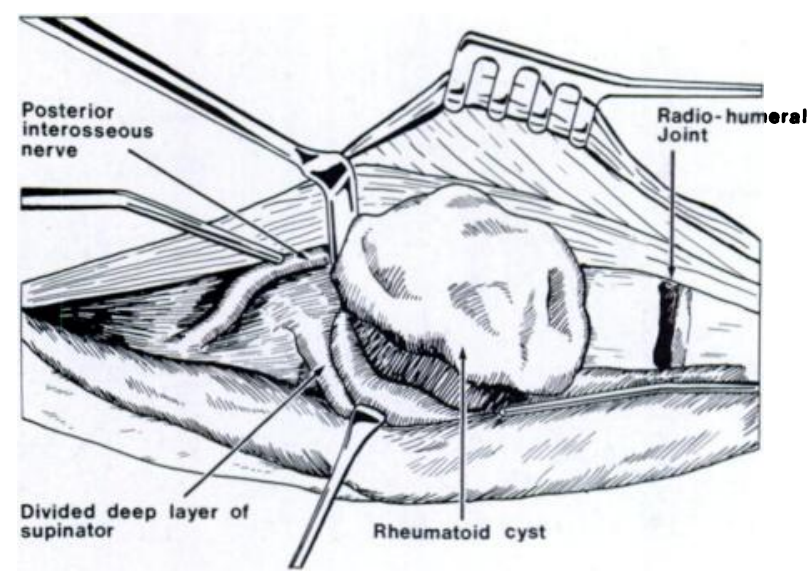

Fig. 4

The deep layer of supinator has been divided to allow enucleation of the rheumatoid cyst.

elbow joint. A lively splint was worn postoperatively to extend the digits. Four days later there was some return of extensor power but this was not complete until six months after operation.

The right side. Two months after the operation on his left arm the patient developed a posterior interosseous nerve palsy on the right, with paralysis of the finger extensors, most marked on the ulnar side. As on the first side, he had weakness of extensor carpi ulnaris, no sensory changes and a normal tenodesis test. Plain radiographs showed less severe rheumatoid involvement of the elbow and arthrography showed generalised synovial pouching but no cyst.

Aspiration of the elbow joint was performed and $40 \mathrm{mg}$ of methyl prednisolone injected. Six weeks later the synovitis had diminished and nerve function had improved. A further $40 \mathrm{mg}$ injection of steroid was given, but although the finger extensors remained moderately 
strong, the power of extensor pollicis longus decreased. The arm was explored three months after the onset of symptoms. On this occasion a modified Henry's anterolateral approach was used (Edmonson and Crenshaw 1980). Biceps and brachioradialis were separated to expose the interval between brachialis and brachioradialis (Fig. 5). A leash of vessels from the recurrent branch of the radial artery overlay the division of the radial nerve into its superficial branch and the posterior interosseous nerve. The vessels were ligated and divided and the posterior interosseous nerve could then be clearly seen passing behind the arcade of Frohse within $1 \mathrm{~cm}$ of the origin of the nerve (Fig. 6). The entire rim of the arcade was fibrous, and when this was divided the undersurface of supinator was also fibrous. Decompression of the nerve was secured by dividing this aponeurosis distally for $2.5 \mathrm{~cm}$ (Fig. 7). There was no cystic swelling. The radiohumeral joint was exposed by an anterior capsulotomy, to reveal reasonably preserved articular cartilage. A limited synovectomy was performed. A lively splint was worn postoperatively and by four weeks some recovery of extensor power was evident. This continues to improve after three months.

\section{DISCUSSION}

Compression of the posterior interosseous nerve occurs as a complication of rheumatoid arthritis, usually in a female patient with chronic disease (Table I). The patient presents with weakness of the hand due to partial or complete paralysis of the long extensors of all the digits, with the little and ring fingers most severely affected. Dorsiflexion of the wrist is weak and accompanied by radial deviation due to weakness of

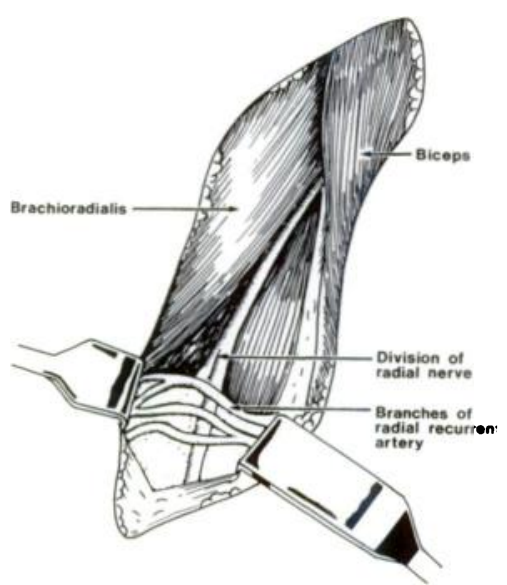

Fig. 5

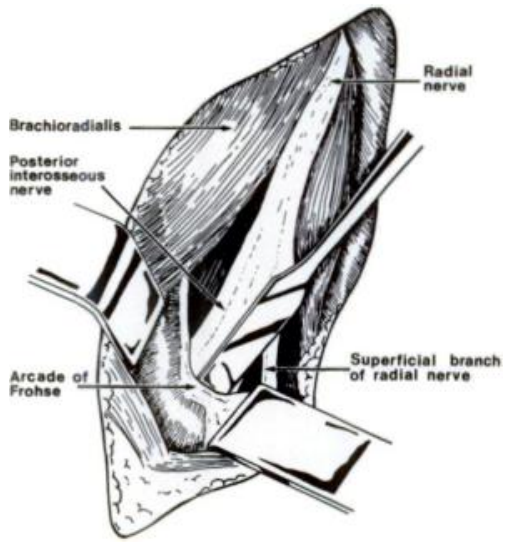

Fig. 6

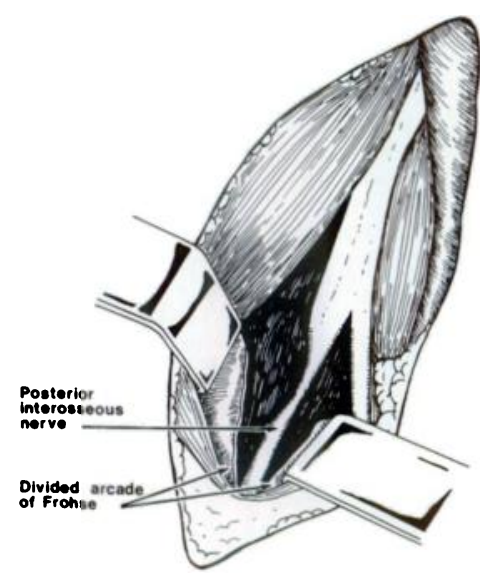

Fig. 7

Anterolateral approach. Figure 5 - Brachioradialis and biceps are being retracted, but the division of the radial nerve is still obscured by the branches of the radial recurrent artery. Figure 6 - A probe has been insinuated behind the tight fibrous arcade of Frohse, against which the posterior interosseous nerve is being compressed. Figure 7 - The arcade of Frohse has been divided and the posterior interosseous nerve is now free.

Table I. Diagnosis, treatment and results in eight cases of posterior interosseous nerve palsy in rheumatoid patients

\begin{tabular}{|c|c|c|c|c|c|}
\hline Authors & $\begin{array}{l}\text { Age } \\
\text { and } \\
\text { sex }\end{array}$ & $\begin{array}{l}\text { Duration of } \\
\text { meumatoid arthritis } \\
\text { in years }\end{array}$ & $\begin{array}{l}\text { Delay before } \\
\text { diagnosis }\end{array}$ & Treatment & Result \\
\hline Marmor et al. 1967 & $71 \mathrm{~F}$ & "Many" & 11 days & $\begin{array}{l}\text { Steroid injection } \\
\text { Decompression }\end{array}$ & $\begin{array}{l}\text { Poor } \\
\text { Good }\end{array}$ \\
\hline Chang et al. 1972 & $-F$ & 4 & 3 weeks & $\begin{array}{l}\text { Systemic steroids } \\
\text { Decompression }\end{array}$ & $\begin{array}{l}\text { Poor } \\
\text { Excellent }\end{array}$ \\
\hline Millender et al. 1973 & $\begin{array}{l}51 \mathrm{~F} \\
49 \mathrm{~F} \\
65 \mathrm{~F}\end{array}$ & $\begin{array}{l}16 \\
8 \\
\text { "Long history" }\end{array}$ & $\begin{array}{l}2 \text { years } \\
1 \text { week } \\
3 \text { weeks }\end{array}$ & $\begin{array}{l}\text { None } \\
\text { Steroid injection } \\
\text { Decompression }\end{array}$ & $\begin{array}{l}\text { Poor } \\
\text { Good } \\
\text { Excellent }\end{array}$ \\
\hline Roth et al. 1986 & $59 \mathrm{~F}$ & 12 & 10 days & Decompression & Excellent \\
\hline White et al. 1988 & $\begin{array}{l}69 \mathrm{M} \\
69 \mathrm{M}\end{array}$ & $\begin{array}{l}3 \\
3\end{array}$ & $\begin{array}{l}6 \text { weeks } \\
2 \text { weeks }\end{array}$ & $\begin{array}{l}\text { Decompression } \\
\text { Steroid injections } \\
\text { Decompression }\end{array}$ & $\begin{array}{l}\text { Excellent } \\
\text { Poor } \\
\text { Good }\end{array}$ \\
\hline
\end{tabular}


extensor carpi ulnaris, although this may be spared (Marmor et al. 1967). The onset of weakness is usually over several days but two patients, including our own, awoke with the condition (Chang et al. 1972). Most patients also experienced pain at the elbow. A delay of several weeks before diagnosis is not unusual.

The differential diagnosis is from extensor tendon rupture. This, however, occurs abruptly, many patients clearly describing the event, and is usually associated with dorsal tenosynovitis and/or subluxation of the distal end of the ulna (Cracchiolo and Marmor 1969). Many patients with rheumatoid arthritis will have pain, synovitis and limited movement at both the wrist and the elbow, obscuring the normally observable line of the extensor tendons and producing a degree of forearm muscle wasting. The tenodesis test is a useful means of distinguishing the two conditions clinically.

Table II. Suggested management of posterior interosseous nerve palsy in rheumatoid arthritic patients.

\begin{tabular}{ll}
\hline Diagnosis & Treatment \\
\hline $\begin{array}{l}\text { Nerve compression from bulging } \\
\text { synovium alone }\end{array}$ & Anterior decompression \\
Nerve compression from cyst & $\begin{array}{l}\text { Posterior decompression and } \\
\text { cystectomy }\end{array}$ \\
$\begin{array}{l}\text { Nerve compression with severely } \\
\text { degenerate joint }\end{array}$ & $\begin{array}{l}\text { Posterior decompression, excision of } \\
\text { radial head and synovectomy }\end{array}$ \\
\hline
\end{tabular}

Electromyography and sensory nerve conduction studies confirm the diagnosis, document the degree of involvement of the posterior interosseous nerve, and may delineate any coincidental damage to the ulnar and median nerves which are also commonly affected in chronic rheumatoid disease at the elbow and wrist respectively. Arthrography of the elbow is of value in demonstrating the presence of a cystic extension of synovium from the elbow joint (Roth et al. 1986). It was useful in our patient since it showed the cyst on one side, and provided information about the state of the articular cartilage, which influenced the choice of treatment.

There is no clear guidance in the literature as to the management of posterior interosseous palsy in rheumatoid arthritis. We undertook surgical decompression on one side and steroid therapy on the other, but found the latter disappointing. Whilst spontaneous recovery without treatment has been described in non-rheumatoid bursitis (Kruse 1958), this has not been the experience in rheumatoid disease (Millender et al. 1973). Steroid injection of the elbow joint produced a good initial result in two reported cases (Millender et al. 1973) but one of them relapsed after six months (Marmor et al. 1967). Chang et al. (1972) used high dose systemic steroids to no avail, whilst in our case, symptoms and signs waxed and waned after injection. Mulholland (1966) pointed out that delay in surgical decompression reduced the chance of successful recovery from posterior interosseous nerve palsy in general. Surgical decompression produced good or excellent results in a total of six reported cases. We therefore recommend that early surgical decompression is the treatment of choice for this condition and that steroid injection should be regarded as a temporising measure only.

Anterolateral (Millender et al. 1973) and posterolateral approaches (Chang et al. 1973) have been used for decompression. Where there is a cyst, or where excision of the radial head and synovectomy is required, the posterolateral route provides the best exposure (Table II). The decision to remove the radial head depends upon the condition of the joint surfaces. In cases where access is required only to the arcade of Frohse, the anterolateral approach is more appropriate.

\section{REFERENCES}

Chang LW, Gowans JD, Granger CV, et al. Entrapment neuropathy of the posterior interosseous nerve: a complication of rheumatoid arthritis. Arthritis Rheum 1972;15:350-2.

Cracchiolo A III, Marmor L. Resection of the distal ulna in rheumatoid arthritis. Arthritis Rheum 1969;12:415-22.

Edmonson AS, Crenshaw AH. Campbell's operative orthopaedics 6th ed. St Louis, etc: CV Mosby, 1980.

Frohse F, Fränkel M. Die Muskeln des menlischen Armes. Jena : Fischer, 1908.

Henry AK. Extensile exposure. 2nd ed. Edinburgh, etc: Churchill Livingstone, 1973.

Kruse F Jr. Paralysis of the dorsal interosseous nerve not due to direct trauma: a case showing spontaneous recovery. Neurology $1958 ; 8: 307-8$.

Marmor L, Lawrence JF, Dubois EL. Posterior interosseous nerve palsy due to rheumatoid arthritis. J Bone Joint Surg [Am] $1967 ; 49-A: 381-3$.

Millender LH, Nalebuff EA, Holdsworth DE. Posterior interosseousnerve syndrome secondary to rheumatoid synovitis. $J$ Bone Joint Surg [Am] 1973;55-A:753-7.

Mulholland RC. Non-traumatic progressive paralysis of the posterior interosseous nerve. J Bone Joint Surg [Br] 1966;48-B:781-5.

Roth AI, Stulberg BN, Fleegler EJ, Belhobek GH. Elbow arthrography in the evaluation of posterior interosseous nerve compression in rheumatoid arthritis. J Hand Surg [Br] 1986;11:120-2. 